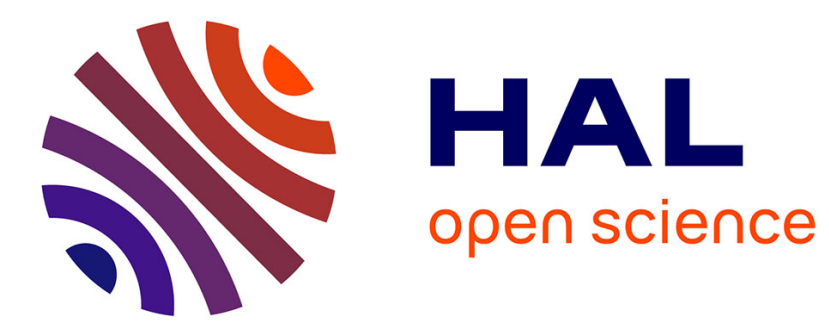

\title{
X-RAY REFLECTIVITY STUDY OF SURFACE MELTING ON Pb (110)
}

J. Gay, B. Pluis, J. Frenken, S. Gierlotka, J.F. van Der Veen, J. Macdonald, A. Williams, N. Piggins, J. Als-Nielsen

\section{> To cite this version:}

J. Gay, B. Pluis, J. Frenken, S. Gierlotka, J.F. van Der Veen, et al.. X-RAY REFLECTIVITY STUDY OF SURFACE MELTING ON Pb (110). Journal de Physique Colloques, 1989, 50 (C7), pp.C7-289-C7-293. 10.1051/jphyscol:1989730 • jpa-00229897

\section{HAL Id: jpa-00229897 https://hal.science/jpa-00229897}

Submitted on 1 Jan 1989

HAL is a multi-disciplinary open access archive for the deposit and dissemination of scientific research documents, whether they are published or not. The documents may come from teaching and research institutions in France or abroad, or from public or private research centers.
L'archive ouverte pluridisciplinaire HAL, est destinée au dépôt et à la diffusion de documents scientifiques de niveau recherche, publiés ou non, émanant des établissements d'enseignement et de recherche français ou étrangers, des laboratoires publics ou privés. 


\section{X-RAY REFLECTIVITY STUDY OF SURFACE MELTING ON Pb (110)}

J.M. GAY (1) , B. PLUIS, J.W.M. FRENKEN, S. GIERLOTKA, J.F. VAN DER VEEN, J.E. MACDONÁLD*, A.A. WILLIAMS*, N. PIGGINS" ${ }^{*}$ and J. ALS-NIELSEN" FOM-Institute for Atomic and Molecular Physics, Kruislaan 407, NL-1098 SJ Amsterdam, The Netherlands "University of Wales, College of Cardiff, GB-Cardiff CF1 3TH, Great-Britain

* University of Leicester, GB-Leicester LE1 7RH, Great-Britain

** Risø National Laboratory, DK-4000 Roskilde, Denmark

Résumé Le profil de densité au voisinage de la surface du $\mathrm{Pb}(110)$ est mesuré par réflectivité de rayons $x$ synchrotron a des températures juste inférieures à celle du point triple. La présence d'une mince couche de surface avec une densité semblable a celle du liquide est mise en évidence. On détermine l'épaisseur de la couche quasiliquide ainsi que la largeur des interfaces solidelquasiliquide et quasiliquidelvapeur.

Abstract The density profile in the near-surface region of $\mathrm{Pb}(110)$ is probed by synchrotron $x$-ray reflectivity measurements at temperatures just below the triple point. They reveal the presence of a thin surface layer of liquid-like density. The thickness of the quasiliquid layer is determined as well as the widths of the solid/quasiliquid and quasiliquid/vapour interfaces.

During the past few years, the phenomenon of surface melting has attracted much interest. It is now generally accepted that the melting of a crystal may be surface-initiated and that a solid crystal may be covered by a quasiliquid layer (QLL) at temperatures below the triple point $\left(T_{m}\right)$. Numerous theoretical and experimental studies are currently performed in order to characterize the QLL /1/.

Surface melting of $\mathrm{Pb}(110)$ has been studied by ion scattering /2,3/, quasi-elastic He scattering /4/, electron /5/ and X-ray /6/ diffraction. Of principal interest are the temperature dependence of the QLL thickness /2,3,6/, the atom mobility in the molten layer /4/ and the crystalline order $/ 2-6 \%$. All these studies yield evidence of surface melting of $\mathrm{Pb}(110)$. However, the $\mathrm{X}$-ray scattering experiment $/ 6 /$ is in conflict with the ion scattering results with regard to the temperature

\footnotetext{
(1) Permanent ađdress : CRMC2-CNRS, Département de Physique, Faculté des Sciences de Luminy. Case 901, F-13288 Marseille Cedex 9, France
} 
dependence of the molten layer thickness.

Here, we report the first synchrotron X-ray reflectivity measurements on a melting surface. This technique is widely used for the characterization of liquid and liquid-crystal surfaces $\Pi I$ and has recently been applied to the study of surface roughness and relaxation in $\mathrm{Au}(100) / 8 /$. The theory of $\mathrm{X}$-ray reflectivity has been extensively developed $\Pi /$. For a uniform medium terminated with a sharp stepwise interface to the vapour, the $\mathrm{X}$-ray specular reflectivity is described by the Fresnel reflectivity $R_{F}$. For a diffuse or rough interface, the reflectivity $R$ deviates from $R_{F}$ and the deviation provides a measure of the density profile near the surface. Normalised to $R_{F}$, the reflectivity is given by

$$
R(Q) / R_{F}(Q)=\rho(\infty)^{-2}\left|\int \rho^{\prime}(z) \exp \left(i Q^{\prime} \cdot z\right) d z\right|^{2}
$$

where $\rho^{\prime}(z)$ denotes the gradient of the density profile $\rho(z) ; Q$ and $Q^{\prime}$ are the wavevector transfer perpendicular to the surface plane outside and inside the crystal respectively. $\rho(\infty)$ is the density deep in the crystal.

The purpose of this experiment is to probe the density profile in the near-surface region of $\mathrm{Pb}(110)$ by measuring the wavevector transfer dependence of the specular reflectivity for temperatures close to the melting point. Figure 1 shows a schematic view of the scattering geometry and of the two models considered in this study. The first model is a solid with bulk density $\rho_{\mathrm{S}}$ up to the (rough) surface (Figure 1a). In the second model, the solid is covered by a quasiliquid layer of thickness $d$ and with a density $\rho_{1}$ (Figure $1 b$ ). In both cases, the shape of the interfaces is described by an error function erf $[z /(\sqrt{2} \sigma)]$.

The experiments were performed on the wiggler beamline 9.4 of the Synchrotron Radiation Source (SRS) in Daresbury, U. K., using a UHV system and a diffractometer described elsewhere $19,10 \%$. The sample was spark-cut from a single crystal bar of high purity, then mechanically polished. The surface was cleaned by cycles of Ar ion bombardment and annealing. The surface cleanliness was checked with Auger electron spectroscopy. The surface had a macroscopic figure of error of 0.8 degree, FWHM.

Several reflectivity curves were measured at different temperatures below $T_{m}$ $\left(\mathrm{T}_{\mathrm{m}}=600.7 \mathrm{~K}\right)$, using a monochromatic $\mathrm{X}$-ray beam of wavelength $\lambda=1.80 \AA$. At room temperature, the experimental reflectivity is accurately described by the Fresnel reflectivity $R_{F}$, as expected for an atomically flat surface with a sharp interface. As the melting point is approached, the reflectivity deviates substantially from $R_{F}$. Figure 2 shows $R(Q) / R_{F}(Q)$ at $0.2 \mathrm{~K}$ below the melting point. The modulation in $R(Q) / R_{F}(Q)$ clearly demonstrates the existence of a $Q L L$ with an average density different from that of the bulk solid. The thickness of the layer follows from the period of the modulation. The amplitude of the modulation yields the relative density change in the layer whereas the average decrease of $R(Q) / R_{F}(Q)$ with $Q$ provides a measure of the width of the quasiliquid/ vapour interface. 
a)

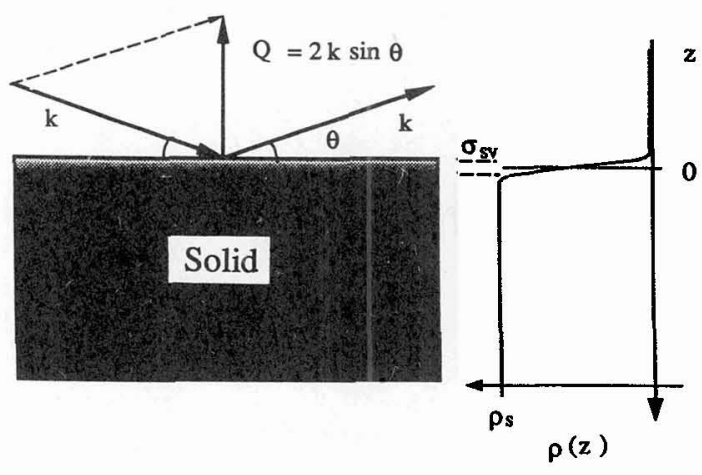

b)

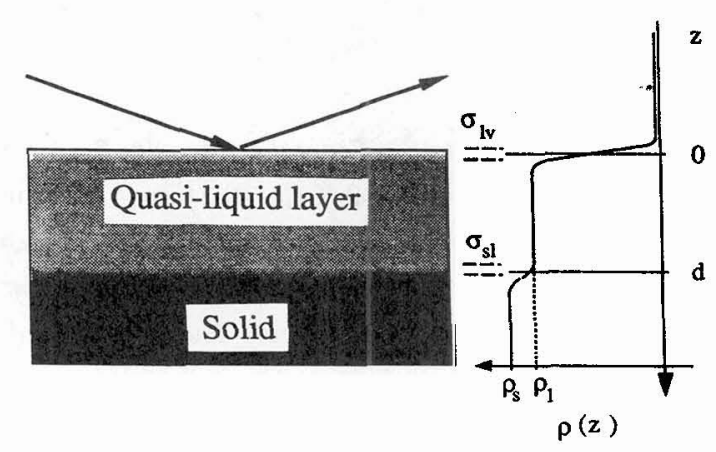

Figure 1: Density profiles for a crystal which is (a) solid up to the surface, and (b) covered with a quasiliquid layer of thickness $d . \rho_{s}$ and $\rho_{l}$ are the average densities in the solid and the quasiliquid layer. $\sigma_{S V}, \sigma_{S l}$ and $\sigma_{I V}$ are the widths of the solid/vapour, solid/quasiliquid and quasiliquid/vapour interfaces respectively. The X-ray scattering geometry is indicated as well.

With equation (1), reflectivity curves were calculated for the two models of figure 1 and fits were made to the measured curves (see figure 2). The first model with a rough non-melted solid surface (figure 1a) can be ruled out since it yields a reflectivity curve which is at large variance with the data (broken curve in figure 2). The best fit from the QLL-model is shown by the solid curve in figure 2. At $T=T_{m}-0.2 \mathrm{~K}$, the QLL thickness is been found to be $d=1.96 \pm 0.25 \mathrm{~nm}$. This value is in good agreement with the ion scattering results $(2.15 \pm 0.15 \mathrm{~nm}) / 3 /$ but much larger than that of the X-ray study /6/. The average density of the QLL is $3.9 \pm 1.2 \%$ smaller than that of solid $\mathrm{Pb}$. This is close to the $3.0 \%$ density difference between bulk solid and liquid at $\mathrm{T}_{\mathrm{m}} / 11 /$. The width of the quasiliquid/vapour interface, $2 \sigma_{1 \mathrm{v}}=0.324 \pm 0.04 \mathrm{~nm}$, is about one atomic diameter, as is expected for a bulk liquid-metal/vapour interface /12/. The width of the density profile at the solid/quasiliquid interface $\left(0.1<2 \sigma_{\mathrm{s} 1}<0.9 \mathrm{~nm}\right)$ is smaller than the width of the crystallinity profile 


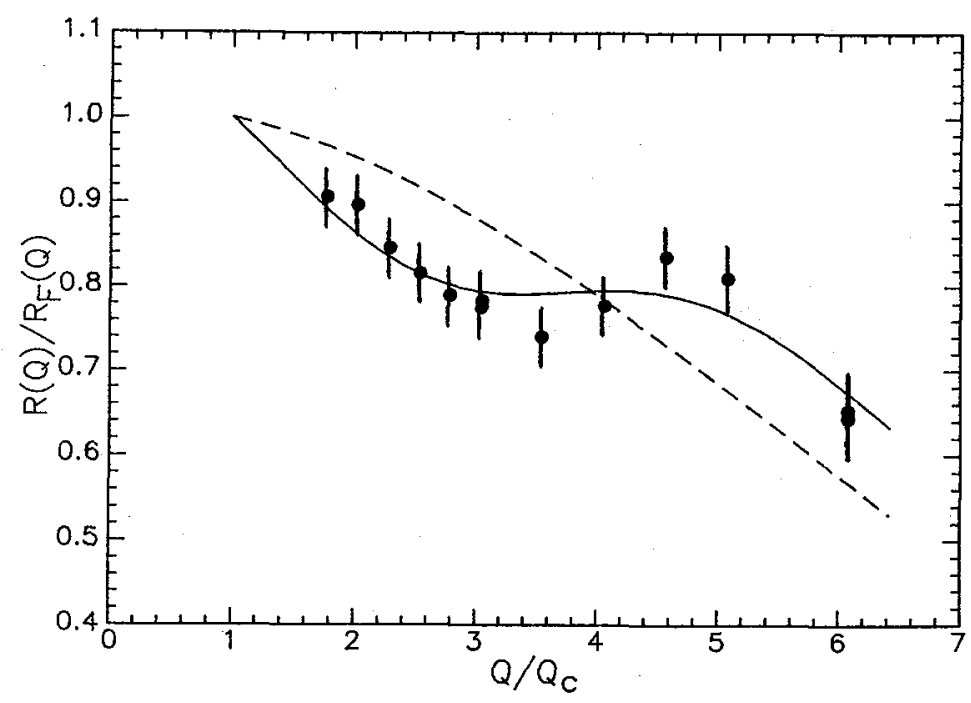

Figure 2: The reflectivity $R(Q)$, normalised to the Fresnel reflectivity $R_{F}(Q)$, versus the reduced perpendicular momentum transfer $Q^{\prime} Q_{c}$ at $T=T_{m} .0 .2 \mathrm{~K} . Q_{c}=0.61 \mathrm{~nm}^{-1}$ is the wavevector transfer corresponding to the critical angle $\theta_{c}$ for total reflection. The solid curve represents the best fit to the data for the QLL-model discussed in the text. The dashed curve is the best fit for a model in which the crystal is assumed to remain solid up to the surface. The presence of a QLL is clearly demonstrated.

found from ion scattering $(1.4 \mathrm{~nm}) / 13 /$; such a situation has been predicted by lattice theory for surface melting of Lennard-Jones crystals $/ 14 \%$.

This study demonstrates the suitability of X-ray reflectivity as a probe of surface melting. Information is obtained on the density profile near the surface. The existence of a quasiliquid layer on top of the $\mathrm{Pb}(110)$ surface, with average density close to that of bulk liquid is clearly shown at $T=T_{m}-0.2 \mathrm{~K}$. The QLL thicknesses used to fit the reflectivity curves at other temperatures below $T_{m}$ are consistent with the ion-scattering results $/ 2,3$, but disagree with the conclusions from the X-ray diffraction study by Fuoss et al./6/. The reason for the discrepancy is not yet understood.

Acknowledgements This work is part of the research program of the Stiching voor Fundamenteel Onderzoek der Materie (FOM) with financial support from the Nederlandse Organisatie voor Wetenschappelijk Onderzoek (NWO). One of us (J.M.G.) thanks the Centre National de la Recherche Scientifique (CNRS) for financial support.

\section{References}

/1/ See, e.g., J.F. van der Veen, B. Pluis and A.W. Denier van der Gon, in "Chemistry and Physics of Solid Surfaces VII", Springer Ser. Surf. Sci., Vol. 10, Eds R. Vanselow and R. 
Howe, Springer Verlag (Berlin, Heidelberg, New York, Tokyo), 1988, and references therein.

/2/ J.W.M. Frenken, P.M. J. Marée and J.F. van der Veen, Phys. Rev. B34 (1986) 7506.

B/ B. Pluis, T.N. Taylor, D. Frenkel and J.F. van der Veen, to be published in Phys. Rev. B. /4/ J.W.M. Frenken, J.P. Toennies and Ch. Wöll, Phys. Rev. Lett. 60 (1988) 1727.

15/ K.C. Prince, U. Breuer and H.P. Bonzel, Phys. Rev, Lett. 60 (1988) 1146.

16/ P.H. Fuoss, L.J. Norton and S. Brennan, Phys. Rev. Lett. 60 (1988) 2046.

17/ See, e.g., J. Als-Nielsen, in Handbook of Synchrotron Radiation, Vol. 3, Eds D.E. Moncton and G.S. Brown, North Holland (Amsterdam).

A. Braslau, P.S. Pershan, G. Swislow, B.M. Ocko and J. Als-Nielsen, Phys. Rev. A38 (1988) 2457.

/8/ D. Gibbs, B.M. Ocko, D.M. Zehner and S.G.J. Mochrie, Phys. Rev. B38 (1988) 7303.

19/ E. Vlieg, A. van't Ent, A.P. de Jongh, H. Neerings and J.F. van der Veen, Nucl. Instr. and Meth. A262 (1987) 522.

/10/ C. Norris, J.S.G. Taylor, P.R. Moore and N.W. Harris, to be published.

/11/ G. Borelius, in "Solid State Physics", Eds F. Seitz and D. Turnbull, Academic Press (New York, London) 1958.

/12/ J.W. Allen and S.A. Rice, J. Chem. Phys. 67 (1977) 5105.

/13/ B. Pluis, D. Frenkel and J.F. van der Veen, to be published.

/14/ A. Trayanov and E. Tosatti, Phys. Rev. B38 (1988) 6961. 